\title{
Rancang Bangun Aplikasi Manajemen Peralatan Pada Jurusan PendidikanTeknik Elektro Berbasis Desktop
}

\author{
Dimas Vio Karim \\ Universitas Negeri Medan, JL. William Iskandar Pasar V Medan, Sumatera Utara, Indonesia \\ e-mail: dimasvio14@gmail.com
}

\begin{abstract}
Abstark-Jurusan Pendidikan Teknik Elektro adalah salah satu Jurusan yang berada di Universitas Negri Medan. Universitas Negeri Medan memiliki banyak alat untuk mendukung kegiatannya. Saat ini Jurusan Pendidikan Teknik Elektrobelum memiliki sistem informasi internal untuk mengendalikan peralatan yang dimiliki. Belum adanya aplikasi manajemen peralatan tentu akan mengalami kesulitan dalam melacak data alat-alat. Solusi untuk mengatasi masalah yang ada, tentu saja membutuhkan sistem informasi manajemen peralatan yang dapat menjalankan manajemen peralatan agar lebih efisien dan terstruktur, serta memfasilitasi pengumpulan data alat,. metode yang digunakan dalam mengembangkan sistem adalah air terjun. Model ini terdiri dari analisis kebutuhan, desain sistem dan perangkat lunak, implementasi dan sistem unit, pengujian sistem, operasi dan pemeliharaan. Dengan adanya Aplikasi manajemen peralatan tersebut maka akan memberikan kemudahan dalam mengelola manajemen alat di Jurusan Pendidikan Teknik Elektro.
\end{abstract}

Kata Kunci: aplikasi, pengolahan data, waterfall, Black Box

\begin{abstract}
The Department of Electrical Engineering Education is one of the majors at Universitas Negeri Medan. Universitas Negeri Medan has many tools to support its activities. At present, the Department of Electrical Engineering Education has an internal information system to control its equipment. The absence of equipment management applications will certainly experience difficulties in tracking down data tools. Solutions to overcome existing problems, of course, require equipment management information systems that can run equipment management to be more efficient and structured, and facilitate data collection tools. the method used in developing the system is a waterfall. This model consists of requirements analysis, system and software design, system and unit implementation, system testing, operation, and maintenance. With the application of equipment management, it will provide convenience in managing tool management in the Department of Electrical Engineering Education.
\end{abstract}

Keywords: application, data processing, waterfalls, Black Box

\section{PENDAHULUAN}

Perguruan tinggi merupakan suatu institusi yang sangat kompleks dalam menjalankan kegiatannya, tentu saja dibutuhkan penerapan Computer Based Information System (CBIS). CBIS adalah sebuah sistem yang memanfaatkan komputer untuk mengolah data yang kompleks menjadi informasi yang berguna[1].

Alat adalah segala sesuatu yang berwujud maupun tak berwujud yang mana memiliki nilai ekonomi dan masa ekonomis guna mendukung kegiatan operasional instansi atau organisasi. Sedangkan manajemen Peralatan adalah sebuah kegiatan merencanakan, pengawasan dan pengorganisasian dalam menggunakan, memperbaiki, merawat dan membeli serta menghilangkan segala peralaatan secara fisik guna memaksimalkan pelayanan dan mengurangi biaya serta resiko dalam mengelola alat berwujud maupun tak berwujud dengan atau tanpa teknologi dalam menjalankan kegiatan operasional [2], tidak adanya sistem informasi dan data yang valid

dalam mengelola Peralatan tentu saja membuat pengelolaan serta laporan data alat menjadi tidak seimbang dan dapat menghambat kegiatan operasional. Jurusan Pendidikan Teknik Elektro adalah salah satu Jurusan yang berada di Universitas Negri Medan. di mana memiliki sarana dan prasarana di dalamnya. Tentu Jurusan tersebut memiliki alat-alat sebagai penunjang kegiatannya seperti meja,proyektor, kursi, papan tulis, komputer, printer, dan yang lainnya. Saat ini Jurusan Pendidikan Teknik Elektro tersebut belum memiliki sistem internal yang dapat mengontrol alat-alat yang dimiliki[3]. Belum adanya sistem informasi manajemen alat tersebut tentu menyebabkan kesulitan dalam pengelolaan data- data alat dalam merencanakan, memperbaiki maupun pada saat membeli alat baru. Permasalahan tersebut dapat menyebabkan pengelola alat kesulitan dalam melakukan pendataan jumlah alat, pendataan kondisi alat itu baik, rusak, ataupun dalam keadaan hilang dan pengelompokan alat berdasarkan jenisnya. Hal tersebut dapat menyebabkan proses laporan alat serta penggantian alat yang rusak pada Jurusan Pendidikan Teknik Elektro Universitas Negeri Medan ini menjadi tidak maksimal. Solusi untuk mengatasi permasalahan yang ada, tentunya perlu sebuah aplikasi dalam pengelolaan alat yang dapat memudahkan manajemen dalam mengelola alat menjadi lebih efisien, efektif, dan terstruktur [4]. Diharapkan dengan dibangunnya aplikasi manajemen peralatan ini, dapat memudahkan pengelola alat untuk melakukan pengelolaan dan pendataan barang-barang yang ada pada Jurusan Pendidikan Teknik ElektroUniversitas Negeri Medan. 


\section{METODE PENELITIAN}

Data yang diperlukan sebagai informasi dan bahan masukan dalam penelitian ini adalahdengan menggunakan data primer maupun data sekunder[5], adapun untuk mendapatkanya dengan beberapa metode antara lain:

\section{a. Studi Literatur}

Merupakan metode yang bersumber pada buku, jurnal, dan sumber bacaan lainnya. Pada umumnya metode ini dilakukan dengan cara mencari, menelaah dan membandingkan penelitian sebelumnya yang berkaitan dengan sistem informasi manajemen alat.

b. Observasi

Merupakan metode yang dilakukan dengan cara datang ke lokasi yang dijadikan tempat pengambilan sampel. Dalam hal ini adalah objek penelitian ataupun permasalahan yang terdapat pada proses kegiatan pengelolaan alat sehingga didapat suatu data yang otentik dan jelas. Pada umumya metode ini dipergunakan saat melakukan analisa pada data yang telah diperoleh ataupun terhadap permasalahan yang ada dan pada saat implementasi dan testing sistem[6].

c. Wawancara

Merupakan sebuah metode yang dilakukan dengan cara tanya jawab terhadap sumber- sumber terkait dengan tujuan untuk memperoleh data-data yang diperlukan oleh peneliti atau tanya jawab terhadap data-data yang kurang dimengerti sehingga didapat kebenarannya pada data tersebut. Pada umumnya metode ini lebih banyak digunakan pada saat sebelum melakukan kegiatan perancangan Aplikasi manajemen alat ini.

\subsection{Metode Pengembangan Aplikasi}

Model pengembangan sistem yang digunakan dalam penelitian ini adalah model waterfall yang ditunjukkan pada Gambar 1. Terdapat lima tahapan dalam waterfal, antara lain:

a. Analisis Kebutuhan

Dalam tahap ini melakukan identifikasi kebutuhan sistem yang sesuai dengan harapan pengguna dan menganalisa sistem yang sedang berjalan saat ini untuk menganalisa kebutuhan guna mendapatkan solusi dari permasalahan. Data-data yang dibutuhkan pada tahapan ini biasanya diperoleh melalui wawancara maupun observasi.

b. Perancangan dan Desain Sistem

Dalam tahap perancangan dan desain sistem ini adalah dengan cara melakukan desain sistem untuk memecahkan permasalahan yang terjadi di mana peneliti merancang sistem berorientasi objek menggunakan Unifield Modeling Language (UML) sebagai pemodelan sistem serta Entity Relationship Diagram (ERD) sebagai gambaran struktur dan relasai data sesuai dengan kebutuhan yang diperlukan.

c. Implementasi dan Pengujian Unit

Dalam tahap ini peneliti melakukan kegiatan pemrograman atau merancang aplikasi untuk pengelolaan alat sesuai dengan desain sistem yang telah dirancang sebelumnya.

Pembuatan aplikasi terdiri unit atau submodul yang kemudian digabungkan menjadi modul yang utuh. [7]. Dalam setiap modul-modul kecil itu dilakukannya pengujian untuk mengetahui apakah aplikasi yang dikembangkan sudah berjalan sesuai dengan fungsi yang diinginkan.

d. Pengujian Aplikasi

Pada tahap ini dilakukan pengujian menggunakan metode pengujian white box di mana peneliti melakukan pengecekan kode- kode program java yang telah dibuat dan pengujian black box untuk melakukan pengecekan hasil keluaran dari aplikasi, apabila hasil keluaran tidak sesuai atau terjadi kesalahan maka akan dilakukannya perbaikan agar hasil keluar dari program sudah sesuai dengan yang diharapkan[5].

e. Instalasi dan Pemeliharaan Aplikasi

Instalasi dan pemeliharaan Aplikasi adalah tahap akhir dalam model waterfall. Aplikasi yang telah dikembangkan diinstalasi untuk bisa digunakan dan kemudian pada proses pemeliharaan aplikasi dengan cara melakukan perbaikan-perbaikan terhadap modul sistem yang belum berjalan sesuai keinginan pihak institusi[8]. 


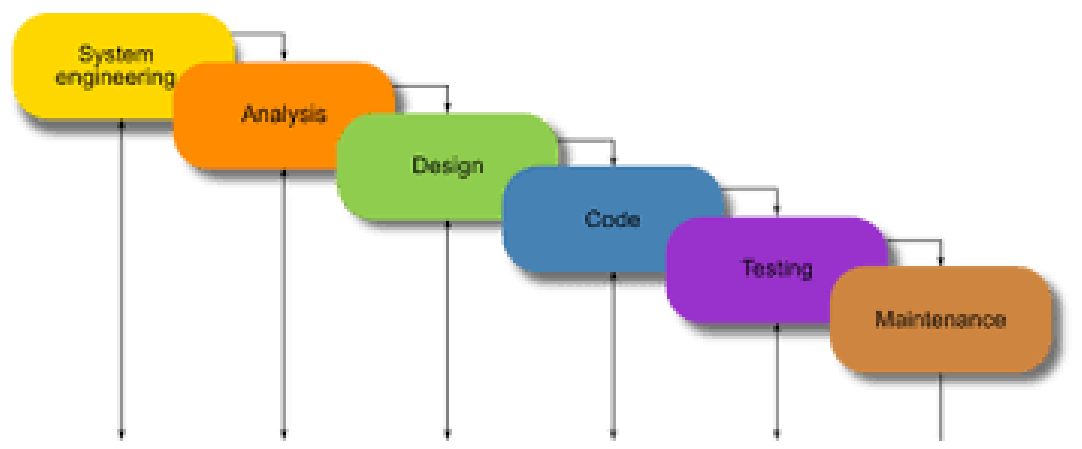

Gambar 1. Metode Pengembangan Waterfall

\subsection{Aplikasi Yang Dikembangkan}

\section{HASIL DAN PEMBAHASAN}

Untuk mengatasi permasalahan yang ada maka diperlukan aplikasi yang dapat melakukan pengelolaan data alat, dimulai dari proses pengalokasian barang atau alat sampai pada proses pelaporan terhadap kondisi alat. Sistem manajemen alat yang dibuat ini menggunakan basis data yang berfungsi untuk menyimpan data dengan jumlah yang banyak[9]. Dengan sistem manajemen alat ini diharapkan dapat memberikan kemudahan dalam pendataan jumlah alat, pendataan alat berdasarkan kondisi alat, dan pengelompokan alat berdasarkan jenisnya. Sistem manajemen alat ini juga dirancang untuk dapat melakukan laporan terhadap kondisi alat yang ada, sehingga diharapkan dapat memberikan kemudahan terhadap pengelola alat dalam melakukan penelusuran data-data alat. Berikut adalah secara umum fitur yang akan dibuat dalam aplikasi usulan meliputi:

a. Admin dan teknisi mempunyai hak akses account yang berbeda untuk login ke dalam aplikasi.

b. Kepala Jurusan dapat melakukan pengelolaan terhadap kondisi alat.

c. Aplikasi ini dilengkapi fitur untuk pelapor dalam membuat laporan terhadap kondisi alat yang ada.

d. Laporan yang telah dibuat oleh pelapor dikirimkan kepada admin dan Kajur.

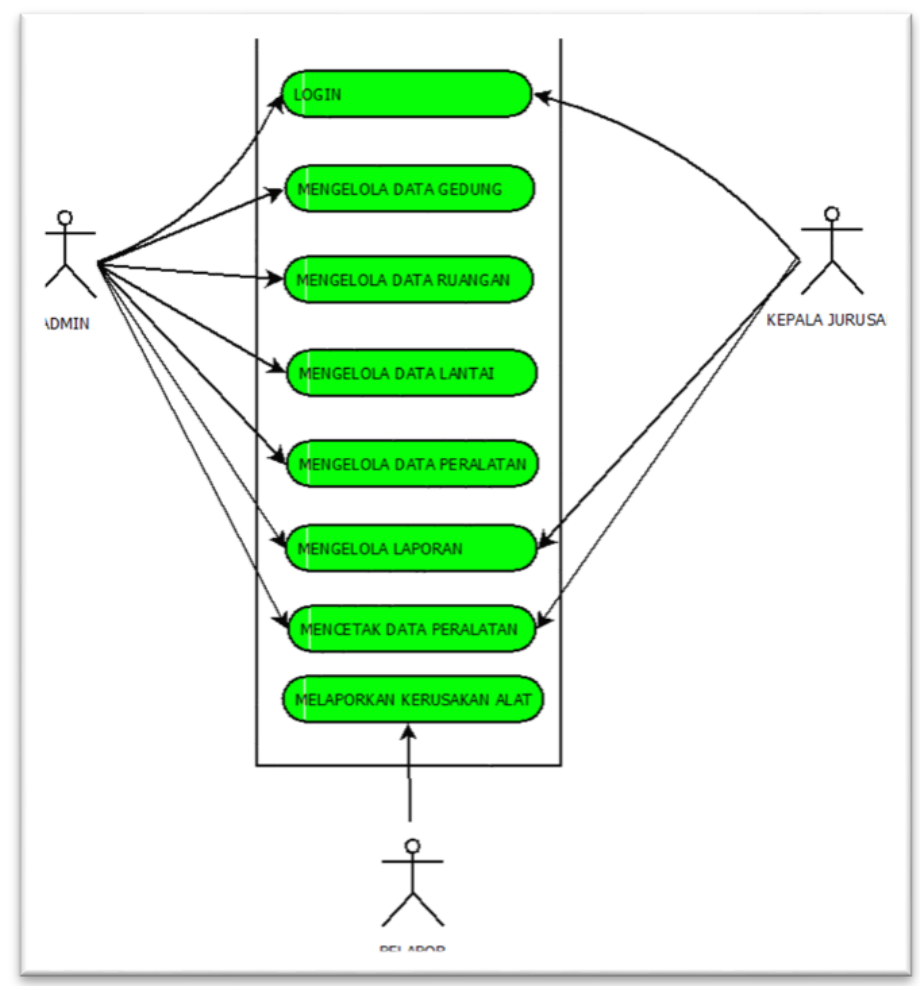

Gambar 2. Use Case Diagram 


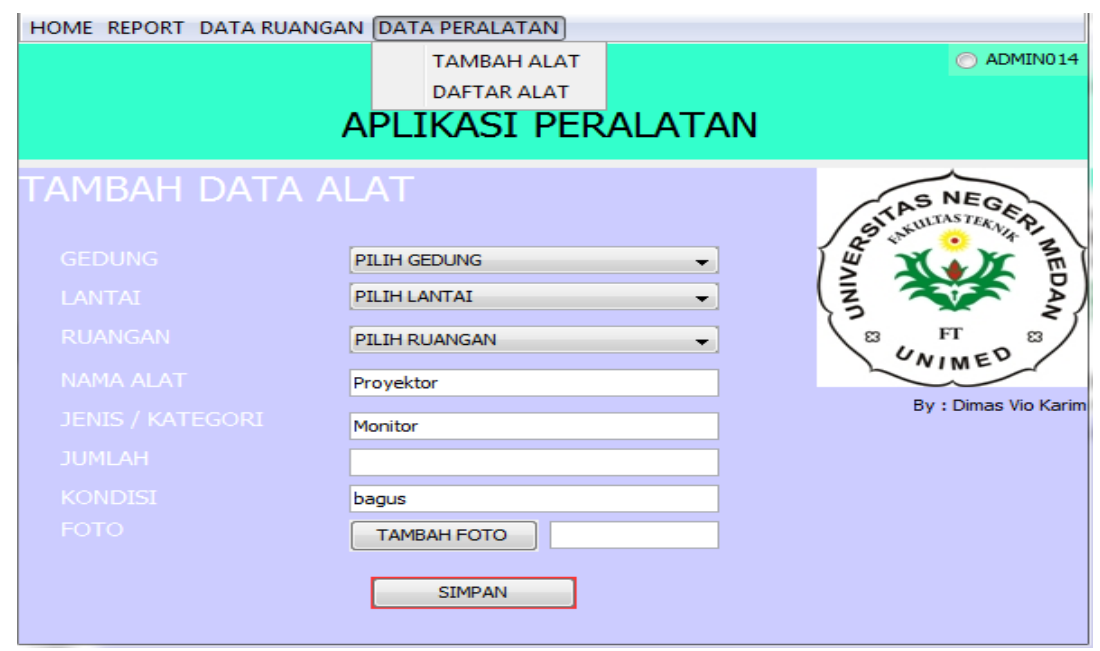

Gambar 3. Tampilan Tambah Data Alat

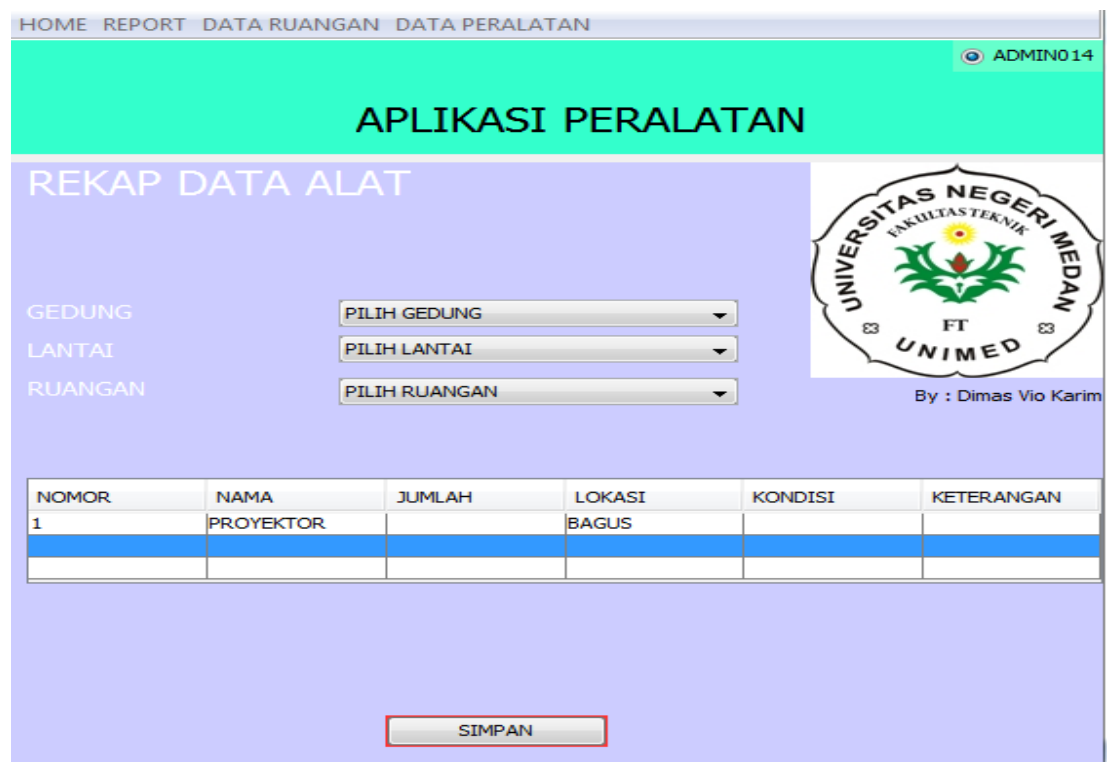

Gambar 4. Tampilan Rekap Data Alat

Pengujian sistem merupakan suatu proses pengujian terhadap kelayakan dan kualitas aplikasi yang telah dibuat. Dalam tahapan ini terdapat dua jenis pengujian yaitu pengujian black box dan white box. Pengujian black-box merupakan jenis pengujian yang bersifat fungsional dari sistem,untuk memastikan bahwa sistem yang dibuat sudah sesuai dengan keinginan dari pengguna tanpa ada kesalahan. Berikut adalah hasil pengujian black box dari aplikasi manajemen peralatan ini.

Tabel 1. Pengujian Black Box pada Halaman Login

\begin{tabular}{|l|l|l|l|}
\hline Deskripsi & Hasil yang Diharapkan & Hasil Pengujian & Kesimpulan \\
\hline $\begin{array}{l}\text { Admin input username } \\
\text { serta password yang } \\
\text { benar. }\end{array}$ & $\begin{array}{l}\text { aplikasi akan menampilkan } \\
\text { halaman utama }\end{array}$ & $\begin{array}{l}\text { Berhasil login dan } \\
\text { aplikasi }\end{array}$ & $\begin{array}{l}\text { J) Berhasil ( ) } \\
\text { Gagal } \\
\text { halaman utama. }\end{array}$ \\
\hline $\begin{array}{l}\text { Mengisi username dan } \\
\text { password yang salah }\end{array}$ & $\begin{array}{l}\text { aplikasi akan menolak akses } \\
\text { login dan menampilkan } \\
\text { pesan " user } \\
\text { tidakditemukan" }\end{array}$ & $\begin{array}{l}\text { aplikasi dapat menolak } \\
\text { akses login dan } \\
\text { menampilkan pesan “ } \\
\text { user tidak ditemukan" }\end{array}$ & $\begin{array}{l}\text { W) Berhasil ( ) } \\
\text { Gagal }\end{array}$ \\
\hline
\end{tabular}




\begin{tabular}{|c|c|c|c|}
\hline $\begin{array}{l}\text { Mengosongkan } \\
\text { username dan langsung } \\
\text { menekan tombol login }\end{array}$ & $\begin{array}{l}\text { aplikasi akan menolak } \\
\text { glogin dan menam } \\
\text { pesan“ username harus } \\
\text { ", }\end{array}$ & $\begin{array}{l}\text { aplikasi dapat menolak } \\
\text { akses login dan } \\
\text { menampilkan pesan } \\
\text { "username harus di isi" }\end{array}$ & \\
\hline $\begin{array}{l}\text { lengosongkan } \\
\text { assword dan langsung } \\
\text { enekan button login }\end{array}$ & $\begin{array}{l}\text { g login dan menampill } \\
\text { pesan " password harus } \\
\text { diisi” }\end{array}$ & $\begin{array}{l}\text { aplikasi dapat menolak } \\
\text { akses login dan } \\
\text { menampilkan pesan } \\
\text { "password harus di isi" }\end{array}$ & $\begin{array}{l}\text { V) Berha } \\
\text { Gagal }\end{array}$ \\
\hline
\end{tabular}

Tabel 2. Pengujian Black Box pada Tambah Alat

\begin{tabular}{|c|c|c|c|}
\hline Deskripsi & Hasil yang Diharapkan & Hasil Pengujian & Kesimpulan \\
\hline $\begin{array}{l}\text { Admin input data alat } \\
\text { dengan mengisi semua } \\
\text { data dan menekan } \\
\text { tombol simpan }\end{array}$ & $\begin{array}{l}\text { Menginput data alat dengan } \\
\text { mengisi semua field, maka } \\
\text { sistem dapat menyimpan } \\
\text { data dan menampilkan pesan } \\
\text { " data berhasil disimpan" } \\
\text { kemudian pada list data alat } \\
\text { akan bertambah }\end{array}$ & $\begin{array}{c}\text { aplikasi dapat } \\
\text { menyimpan data alat, } \\
\text { dan sistem dapat } \\
\text { menampilkan pesan } \\
\text { "data berhasil disimpan" } \\
\text { kemudian pada list data } \\
\text { alat bertambah }\end{array}$ & $\begin{array}{c}\sqrt{ }) \text { Berhasil ( ) } \\
\text { Gagal }\end{array}$ \\
\hline $\begin{array}{l}\text { Admin mengosongkan } \\
\text { data alat kemudian } \\
\text { menekan tombol } \\
\text { simpan }\end{array}$ & $\begin{array}{c}\text { Sistem akan menolak dengan } \\
\text { memberikan informasi pesan } \\
\text { "Data alat harus diisi" }\end{array}$ & $\begin{array}{l}\text { aplikasi dapat menolak } \\
\text { dengan memberikan } \\
\text { informasi pesan "Data } \\
\text { alat harus diisi" }\end{array}$ & $\begin{array}{c}\text { V) Berhasil ( ) } \\
\text { Gagal }\end{array}$ \\
\hline
\end{tabular}

Berdasarkan hasil pengujian di atas dapat diambil kesimpulan yang mana sistem manajemen alat yang telah dibangun memiliki fungsional yang baik dan bebas dari kesalahan serta memberikan hasil yang sesuai harapan.

\section{KESIMPULAN}

Berdasarkan hasil implementasi dan analisa pengujian aplikasi yang telah dibuat dan dilaksanakan, maka disimpulkan bahwa aplikasi manajemen alat ini dibangun dengan model pengembangan waterfall, dan pemodelan perancangan sistem dengan UML, yang mana secara fungsional sesuai dengan yang diharapkan. Dengan dikembangkannya sistem informasi manajemen alat ini dapat memberikan kemudahan pendataan jumlah alat, pendataan kondisi alat, dan pengelompokan alat berdasarkan jenisnya serta memudahkan dalam melakukan penelusuran data-data alat.

\section{DAFTAR PUSTAKA}

[1] Udi and Y. Firmansyah, "Penerapan Metode SDLC Waterfall Dalam Pembuatan Sistem Informasi Akademik,” J. Teknol. Manaj. Inform., vol. 4, no. 1, pp. 184-191, 2018.

[2] J. Riyanto, "Rancang Bangun Sistem Informasi Manajemen Aset Pada Universitas Pamulang Berbasis Web," J. Inform. Univ. Pamulang, vol. 4, no. 1, p. 9, Mar. 2019, doi: 10.32493/informatika.v4i1.2406.

[3] T. Limbong and J. Simarmata, "Menentukan Matakuliah yang Efektif Belajar Daring (Belajar dan Ujian) dengan Metode MultiAttribute Utility Theory (MAUT)," J. Resti, vol. 4, no. 2, pp. 370-376, 2020.

[4] Munir, Multimedia Konsep \& Aplikasi Dalam Pendidikan, vol. 58, no. 12. Bandung: Penerbit Alfabeta, Bandung, 2012.

[5] T. Limbong, Sriadhi, and E. Napitupulu, "Implementation of Linear Congruent Method in Learning Application Batak Toba Script with Game Model," Int. J. Recent Technol. Eng., vol. 8, no. 1, pp. 3984-3988, 2019, doi: 10.35940/ijrte.D8576.118419.

[6] Sugiyono, Metode Penelitian Kuantitatif, Kualitatif dan R\&D. Bandung: PT Alfabet, 2016.

[7] Munawar, "PEMODELAN VISUAL DENGAN UML," 2005. [Online]. Available: https://adoc.tips/pemodelan-visual-dengan-umlmunawar.html. [Accessed: 17-Jun-2020].

[8] T. Limbong and A. H. Hasugian, “Aplikasi e-Directory Berkas Tridharma Kinerja Dosen,” J. Tek. Inform. UNIKA St. Thomas, vol. 1, no. 2, pp. 42-47, 2016.

[9] T. Limbong et al., "Optimization of Employee Assignment in Content Management System Making With Hungarian Method,” 2018. 